Relations industrielles

Industrial Relations

\title{
Stabilité ouvrière et distributisme social
}

\section{Gonzalve Poulin}

Volume 3, numéro 1, septembre 1947

URI : https://id.erudit.org/iderudit/1023557ar

DOI : https://doi.org/10.7202/1023557ar

Aller au sommaire du numéro

Éditeur(s)

Département des relations industrielles de l'Université Laval

ISSN

0034-379X (imprimé)

1703-8138 (numérique)

Découvrir la revue

Citer cet article

Poulin, G. (1947). Stabilité ouvrière et distributisme social. Relations

industrielles / Industrial Relations, 3(1), 8-9. https://doi.org/10.7202/1023557ar

Tous droits réservés @ C Département des relations industrielles de l’Université Laval, 1947
Ce document est protégé par la loi sur le droit d'auteur. L'utilisation des services d'Érudit (y compris la reproduction) est assujettie à sa politique d'utilisation que vous pouvez consulter en ligne.

https://apropos.erudit.org/fr/usagers/politique-dutilisation/ 


\title{
STABILITÉ OUVRIÈRE ET DISTRIBUTISME SOCIAL
}

\author{
Gonzalve POULIN, o.f.m.
}

L'instabilité des classes populaires s'alimente constamment dans la mauvaise distribution des biens. Dans certains pays, comme l'Inde, il ne faut rien moins qu'une transformation des classes sociales pour mettre fin à cette instabilité. Dans les pays à caractèrè capitaliste comme l'Amérique du nord, le salaire devrait être, d'après les théoriciens, le mécanisme normal de distribution et d'équilibre. En fait, comme le capitalisme opère toujours dans des conditions anormales, il arrive que, même dans les contrées à capital abondant, le problème de la juste distribution des biens se pose sur le plan social et nourrit la lutte sans relâche du patronat et du salariat.

Le christianisme social n'a pas attendu le communisme pour dénoncer cette mauvaise condition humaine. Léon XIII, Benoît XV, Pie XI ont tour à tour fait appel à la conscience chrétienne pour remédier aux maux du prolétariat. Lors du récent anniversaire de fondation de l'Action catholique italienne, Pie XII rappelait encore au monde les exigences d'une plus juste distribution des biens dans le monde présent par ces paroles mémorables: «Des événements naturels ont produit une distribution inégale des biens de ce monde, mais l'Eglise est opposée à l'accumulation de ces biens entre les mains d'un groupe de personnes relativement peu nombreuses et excessivement riches tandis que des masses considérables de gens sont condamnées au paupérisme et à une condition économique indigne d'êtres humains ».

\section{Une mauvaise réforme de la richesse}

Tout au cours des siècles, des sectes innombrables ont tenté d'opérer le partage des biens matériels par la violence, le massacre, le vol et l'injustice. La plus récente de ces erreurs et la plus dangereuse pour notre époque, c'est le communisme. La réforme communiste de la richesse repose sur la négation du droit individuel de la propriété. Partout où les communistes ont pu réaliser librement leur programme social, le même processus s'est déroulé à savoir: la persécution des classes possédantes, la confiscation de leurs biens, la substitution de la classe dépossédée par le prolétariat dans la direction des affaires de l'Etat. Ainsi le communisme s'avère-t-il, dans les faits, une révolution de classes et la substitution du prolétariat à la bourgeoisie capitaliste dans la possession de la puissance financière et politique. Cette révolution de la richesse fondée sur le vol, la proscription et la violence, loin d'obtenir une juste stabilité de l'ordre social, ne l'assure que par la force policière et le camp de concentration; ordre social factice qui ne se maintient que par l'injustice et se prépare de sanglantes réactions.

\section{Le vrai distributisme social}

A l'encontre de ce programme erroné de répartition, ceux qui s'inspirent du christianisme social tentent d'établir l'équilibre social sur l'idée de justice et de charité. Loin de nier le droit de propriété, ils veulent le développer par une extension toujours plus grande de ses avantages sociaux. Ce programme est essentiellement fondé sur la collaboration du patron et de l'ouvrier, sur la compréhension toujours plus sympathique de leurs intérêts et de leurs besoins réels et sur une juste appréciation des possibilités concrètes de la conjoncture économique.

Ils ne croient pas à la seule efficience des salaires pour assurer un meilleur équilibre des biens mais ils s'efforcent d'intéresser toute la communauté à un programme de sécurité sociale dont les risques retombent sur tous les citoyens.

C'est ainsi que l'ouvrier québécois a été successivement protégé dans sa vie professionnelle par la Loi des accidents du travail, par l'assurancechômage et par les pensions de vieillesse. Les risques de sa vie familiale ont été couverts par les allocations familiales, par la pension des mères nécessiteuses, par la pension des aveugles, par la loi du département du bien-être social, par la loi de protection de l'enfance, par les lois des écoles d'industries et des écoles professionnelles, par la scolarité obligatoire et gratuite.

Il ne faudrait pas croire toutefois que cette conquête de la sécurité ouvrière sous la civilisation industrielle soit achevée. Les risques de l'âge et de la santé ne sont pas parfaitement couverts par les lois existantes. L'ouvrier a surtout un besoin tragique de toit pour assurer la stabilité de sa vie morale, familiale et sociale.

Le logement constitue, à l'heure présente, la plus urgente insécurité de la classe populaire et c'est sur ce problème que doit se concentrer le 
distributisme social s'il veut rester fidèle à son inspiration chrétienne. ${ }^{1}$

Bien des formules ont été proposées pour résoudre cet angoissant problème. C'est à cause de leur caractère excessif qu'elles restent d'application inefficace. Les différentes lois du logement au Canada et l'opinion publique ont tour à tour fait porter soit sur l'Etat seul, soit sur le propriétaire éventuel toutes les charges de la construction populaire. Les faits ont démontré que le peuplc ne pouvait se prévaloir des lois du logement existantes et que, par contre, il lui était impossible d'assumer seul les frais du logement populaire.

Il est illusoire de croire que la seule politique des salaires peut un jour habiliter le peuple à devenir propriétaire. Par contre, on ne peut exiger du patronat seul ou de l'Etat d'absorber tous les risques du logement ouvrier. C'est donc sur le plan de l'assurance sociale qu'il faut chercher une solution vraiment sociale à ce problème.

L'assurance-logement apparait présentement la seule formule possible et accessible aux salariés canadiens. Une assurance-logement contributoire à laquelle participeraient, pour une part égale, et le salarié et le patron et l'état. Cette assurance qui opèrerait par prêts sans intérêt pourrait construire une trentaine de mille maisons ouvrières, dès sa première année d'opération, et ceci dans la seule province de Québec.

Supposons que la population de Québec accepte cette assurance sociale pour parer au besoin aigu de logements populaires. Tous les employés à gages de la province qui se chiffraient à 815,398 en 1945 contribuent chacun $\$ 0.25$ par semaine pour l'assurance-logement. Les patrons et l'Etat provincial accordent le même montant. L'assurance-logement pourra cumuler chaque mois une somme globale de $\$ 2,446,194$. Même en déduisant des frais d'administration élevés, cette assu- rance permettrait annuellement 30,000 prêts de $\$ 8,000$ pour la construction de logements familiaux à bon marché.

Pourquoi faire assumer par tous les salariés, par l'Etat et par le patronat les charges de lhabitation populaire? Parce que le logement populaire est devenu le plus urgent de nos problèmes sociaux, celui qui intéresse et l'autorité publique et l'ouvrier et le patron, parce qu'il est impossible de faire porter sur l'un de ces trois agents toutes les charges de ce problème à cause de son amplitude, parce que la stabilité sociale constitue présentement la condition essentielle de la paix sociale, parce que, comme le déclarait récemment Pie XII, « une plus juste distribution de la richesse est un objectif social élevé, digne de nos efforts » et que cette distribution ne peut sainement s'opérer que sur le plan de la sécurité ouvrière.

Evidemment, cette assurance-logement ne serait accessible qu'à une catégorie de salariés, celle dont le revenu annuel ne dépasse pas environ $\$ 2,800$; celle qui na pas de propriété; celle qui est riche d'enfants mais pauvre d'argent. Ii suffirait de bien peu d'années d'opération pour permettre à l'assurance-logement de résoudre l'acuité de la crise, ce qui l'autoriserait à diminuer rapidement le taux de ses prestations et même à entreprendre la réalisation de cités ouvrières plus humaines, accessibles à une pleine vie communaire, oublieuses d'aucun des besoins essentiels de l'ouvrier, ceux de sa vie physique, morale, intellectuelle, sociale et religieuse.

Si les chrétiens veulent vraiment convraincre les classes populaires que l'ordre social chrétien dépasse infiniment par ses intérêts, ses avantages et la grandeur de sa vision l'ordre social marxiste, ils ne peuvent pas oublier de fonder cet ordre social chrétien sur la stabilité ouvrière et cette stabilité ouvrière est vaine sans une plus juste distribution des immenses biens de la civilisation moderne.

(1) -N.D.L.R. Au moment où nous allons sous presse, nous apprenons que les Archevêques et Evêques de la province de Québec à leur assemblée pléniaire du 23 setembre ont fait la déclaration suivante:

\&. problème du logement va toujours s'aggravant. Il se fait sentir par la rareté des logis, le prix élevé des matériaux de construction et la difficulté de se les procurer, par les exigences injustes de certains propriétaires qui se refusent à louer leurs maisons aux familles avec enfants.

L'Épiscopat de la province de Québec, douloureusement préoccupé des graves conséquences d'une pareille misère sociale au point de vue population, santé et moralité, prie les gouvernements fédéral, provincial et municial d'aider efficacement à la construction de maisons salubres, familiales et à prix populaires, et de donner la préférence aux familles nombreuses. $\rightarrow$ 